\title{
The Technical Training in Normal Science Students Based on Core Literacy
}

\author{
Guoxing Dai \\ Department of Mathematics and Applied Mathematics \\ Jiangsu University \\ Zhenjiang, China \\ daigx@163.com \\ Xingxing Sun \\ Department of Mathematics and Applied Mathematics \\ Jiangsu University \\ Zhenjiang, China \\ 957651371@qq.com
}

\author{
Yunxia Wu \\ Department of Mathematics and Applied Mathematics \\ Jiangsu University \\ Zhenjiang, China \\ 1533129221@qq.com \\ Xinyue You \\ Department of Mathematics and Applied Mathematics \\ Jiangsu University \\ Zhenjiang, China \\ 1015288567@qq.com
}

\begin{abstract}
The subject takes the problems in the evaluation of normal science students ' technical training as the starting point of the study. With regard to the 33 items of regular training, the Open Questionnaire is designed to conduct a qualitative survey of 134 mathematics normal science students (who are already employed, obtain te acher preparation, and are graduates), about the "Mathematics normal science students' core literacy". This paper uses data analysis software (SPSS) to analyze data to build a core literacy model based on factor correlation analysis to reduce the dimensions associated with core literacy. It conducts MDS analysis in different dimensions to obtain a close relationship between training programs and the need to focus on and understand the core literacy contents and training approaches of mathematics students from different dimensions.
\end{abstract}

Keywords-Core Literacy; Factor Analysis; Technical Training; Professional Growth

The so-called "students' development of Core Literacy" mainly refers to necessary qualities and key abilities that students should be able to adapt to the needs of lifelong development and social development. Currently, the concept of core literacy is vividly embraced by the education circles and gradually become the mainstream of education reform. The emergence of core literacy has triggered education courses and major changes in personnel training. The special role of normal science students as "current students" and "future teachers" is not only the main body of core literacy, but also the guider who cultivates students' core qualities in the future. In order to adapt to the development of modern education, some colleges develop the technological training methods of normal science students by the cloud teaching model, and discovery four aspects of core literacy: learning ability, language ability, cultural character and ideological quality. In the practice of normal science students, the first three aspects are summarized

Guoxing Dai, Department of Mathematics and Applied Mathematics, College of Science, Jiangsu University, Associate Professor, Master of Soft ware Engineering; 301 Xuefu Road, Zhenjiang, Jiangsu, China,212013

Key Projects of Jiangsu University's Teaching Reform: Based on Big Data Analysis Research on the Construction of "RTE Integration" Normal School Students' Skills Mixing Training Platform (2017JGZD017); Jiangsu University Students' Scientific Research Projects (16A90, 16C407) as professional skills, and the latter is summarized as professional quality.

\section{Status Quo of Normal Science Students ’Technical TRAINING UNDER CORE LITERACY}

In 2014, the Ministry of Education issued the "Opinions on Deepening the Reform of the Curriculum and Implementing the Basic Tasks of 'Improve people's morality and cultivate talents"”. It is proposed that "The Ministry of Education will organize and research the development of the core literacy system for students in each segment to clarify the necessary qualities and critical abilities that students should possess to meet the needs of lifelong development and social development [1]." Core literacy is the necessary character and key ability that students form gradually to meet the needs of individual's lifelong development and social development during the course of receiving corresponding education. It is a combination of students' knowledge, skills, emotions, attitudes, values, and many other requirements. It integrates learning ability, language ability, cultural character, and ideological quality in the normal course design in this study.

Currently, under the influence of core literacy, all normal universities have begun to pay attention to applied research in this area. The domestic research on the professional skills and professional qualities of students in the normal university includes "Study on the Status Quo of the Cultivation of Professional Skills of Normal College Students", "Study on the status quo and effective training methods of the professional skills of normal college students", "Breakthroughs and Transitions: Teachers' Core Accomplishments in Teacher Training and Improvement Research”, “A Preliminary Study on Cultivation of Normal University Students' Core Literacy"[2], "A Study on the Application of Virtual Simulation Experimental Platform to Faculty Students' Cultivation of Core Literacy"[3] and etc. These dissertations 
are aimed at discussing the prevailing skills training of normal science students and the dilemma and direction of the reform of normal science students training under the core literacy requirements, so as to achieve the upgrading of normal science students ' core skills in normal student' technological training.

Through the analysis of the above thesis, it can be found that most of the researches are about systematic theories and they do not implement specific training content and aspects. In order to make a clear and profound study of the effect of teacher skill training on core literacy, this study conducts a thorough mining and analysis of the complex relationship between specialized professional literacy through factor analysis, dimension reduction, accurate categorize to explore the relationship between skills training and core literacy.

\section{The Design of the Study And Analysis Methods}

\section{A. Sources of data}

The data of this study is based on the online survey of the "Study on Skills Training and Core Literacy of Normal science students under Cloud Education" implemented by the University of Jiangsu in 2017. The survey targets include students who have already been employed, passed the test, and are in the school's normal schools. Answering the questions in the natural state without any influence, mainly online questionnaires, a total of 140 were recovered. According to the principle of the answer time and the quality standards of the questionnaires, 134 questionnaires were selected as valid questionnaires with an effective rate of $95.7 \%$. The content involves lectures, readings, competition participation, teaching software, and other 33 variable data. The internal consistency coefficient of each topic is about 0.8 and reliability is more reliable.

\section{B. Core Literacy Model}

This model is a core literacy model, which is based on the structure of 'Implementation--Process-- Effect', and describes the effects of professional skills and professional accomplishments on the core literacy of normal science students [4]. The model comprehensively and profoundly includes the influence of both skills and attitudes. It systematically considers the four aspects of language ability, learning ability, cultural character and ideological quality, and provides a good theoretical basis and conceptual framework for the study of core literacy models.

Based on the above four aspects, the questionnaire was designed, and the following indicators are condensed: language, including communication skills, logical thinking and so on; skills, including board-writing, class-telling, standing posture, and use of teaching aids; the use of information technology, including: geometric drawing board, micro teaching, professional knowledge and so on.

Through these indicators, the structure of 'Implementation-Process-- Effect" is reflected. Based on this framework, we study the impact of teacher skills training on core literacy in cloud teaching.

\section{Analysis Methods}

In the course of research, it was found that indicators such as language ability and learning ability overlap each other and interact with each other to a large extent. There is a complex network structure between the indicators. The focus of this study is on the impact of professional skills and professional literacy on core literacy. It involves the direct and indirect correlations between multiple sets of variables, and the base of the variables is too large, and conventional correlation and linear analysis have been ineffective. In order to further meticulously characterize these influencing factors, factorial analysis is used to reduce the dimensionality of design indicators. Then further in-depth analysis through the new index after dimension reduction.

\section{Analysis of Factors Related to Students' Core LITERACY}

Language competence indicators include communication ability, tone and intonation, logical thinking, teacher-student interaction and language expression; learning ability indicators include teaching skills, the use of information technology, professional knowledge, collaborative exploration and reflection, and knowledge applications; cultural and personality indicators include creating problem situations. Information skills knowledge, pedagogy knowledge, psychology knowledge, professional knowledge accomplishment, and cultural common sense; ideological quality indicators include training attitudes, training goals, step by step, exchanges and cooperation, summarization and reflection, lifelong learning. Because there is a certain correlation between these variables and there are a large number of variables, it is necessary to use factor analysis methods to reduce the dimension of data.

\section{TABLE I. KMO AND BARTLETT TEST}

\begin{tabular}{c|c|c}
\multicolumn{2}{c|}{ KMO-sampling-suitability-measure.r } & .659. \\
\hline \multirow{3}{*}{ Bartlett-spherical test. } & $\begin{array}{c}\text { Approximate-Chi- } \\
\text { square.r }\end{array}$ & 659.416. \\
\cline { 2 - 3 } & \begin{tabular}{c} 
Degree-of-freedom.r \\
\cline { 2 - 3 }
\end{tabular} & 276.1 \\
\cline { 2 - 3 } & Significant. & .000.
\end{tabular}

Where are in table 1 that KMO and spherical Bartlett test results for factor analysis. The KMO statistic is 0.659 , which means that the information between the variables has a high degree of overlap, so that the effect of factor analysis is better. At the same time, it can be seen from the Bartlett test that the independent hypothesis of each variable should be rejected, that is, there is a strong correlation between variables [5]. 
TABLE II. INTERPRET ATION OF TOT AL VARIANCE

\begin{tabular}{|c|c|c|c|c|c|c|c|c|c|}
\hline \multicolumn{4}{|c|}{ Initial feature value } & \multicolumn{3}{|c|}{ Extract the square sum of loads } & \multicolumn{3}{|c|}{ Sum of squared rotation loads } \\
\hline & Total & $\begin{array}{l}\text { Variance } \\
\text { percentage }\end{array}$ & Accumulation $\%$ & Total & $\begin{array}{l}\text { Variance } \\
\text { percentage }\end{array}$ & Accumulation \% & Total & $\begin{array}{l}\text { Variance } \\
\text { percentage }\end{array}$ & Accumulabin \% \\
\hline 1 & 3.864 & 16.100 & 16.100 & 3.864 & 16.100 & 16.100 & 2.557 & 10.655 & 10.655 \\
\hline 2 & 2.180 & 9.085 & 25.185 & 2.180 & 9.085 & 25.185 & 2.046 & 8.526 & 19.181 \\
\hline 3 & 1.763 & 7.345 & 32.529 & 1.763 & 7.345 & 32.529 & 1.880 & 7.835 & 27.016 \\
\hline 4 & 1.599 & 6.661 & 39.190 & 1.599 & 6.661 & 39.190 & 1.786 & 7.442 & 34.458 \\
\hline 5 & 1.511 & 6.296 & 45.486 & 1.511 & 6.296 & 45.486 & 1.764 & 7.351 & 41.809 \\
\hline 6 & 1.270 & 5.292 & 50.779 & 1.270 & 5.292 & 50.779 & 1.420 & 5.916 & 47.725 \\
\hline 7 & 1.141 & 4.755 & 55.533 & 1.141 & 4.755 & 55.533 & 1.344 & 5.599 & 53.324 \\
\hline 8 & 1.080 & 4.501 & 60.034 & 1.080 & 4.501 & 60.034 & 1.323 & 5.514 & 58.838 \\
\hline 9 & 1.014 & 4.227 & 64.261 & 1.014 & 4.227 & 64.261 & 1.302 & 5.423 & 64.261 \\
\hline
\end{tabular}

Table 2 shows the variance contribution rate and cumulative contribution rate of each factor. It can be seen that the eigenvalues of the first nine factors are greater than 1 , the variance of the first factor accounts for $16.1 \%$ of the variance of all factors, and the cumulative variance contribution rate of the first nine factors reaches $64.261 \%$. Therefore, the first nine factors are enough to describe factors such as language ability, learning ability, cultural character, and ideological quality. In order to make the coefficient in the factor load matrix more significant, the initial factor load matrix is rotated by the maximum variance method, and the cumulative variance contribution rate after rotation remains basically unchanged.

In the study, the relevant variables in professional skills are reduced through Spss to obtain the rotated factor load matrix as shown in Table 3.

TABLE III. ROT ATED COMPONENT MATRIX A

\begin{tabular}{|c|c|c|c|c|c|c|c|c|c|}
\hline & 1. & 2. & 3. & 4. & 5. & 6. & 7. & 8. & 9. \\
\hline Question 6 (B. Question) & .770 & -.017 & -203. & .045 & -.053 & .022 & .024 & -.015 & .014 \\
\hline Question 5 (B. Question). & .762 & .080 & -.115 & .052. & .025 & -.080 & -.063 & .064 & .080 \\
\hline Question 5 (E. Ruler Drawing Explained). & .604 & .289. & .365 & .204. & .077 & .119. & -.018 & .190 & .004 \\
\hline Question 5.(D. speak) & .504 & .377 & -.084 & -.135 & .127. & .017 & .167. & .132. & .208. \\
\hline Question 6. (F. Ruler Drawing Explained) & .490 & .282 & 241. & .236 & .053. & .104 & -160 & .440 & -.024 \\
\hline Question 6. (E. Board) & .108. & .730 & .084 & .149. & .078 & .106. & .011. & -.230 & -.135 \\
\hline Question 5. (C. Lecture) & .021. & .723 & 041 & -.229 & .047. & -.079 & -.037 & 154 & 172. \\
\hline Question 6.(D. speak) & .245 & .602 & -.140 & .330 & .087 & .039 & -.023 & -.009 & .083. \\
\hline Question 7.(B. Sketchyad) & .072. & .100 & -.728 & -.141. & -.248 & -.017. & -.096 & .046 & .000 \\
\hline $\begin{array}{l}\text { 9. How many books do you spend on average about one month. } \\
\text { outside your major? }\end{array}$ & -106 & .152 & .677 & -.043 & -169 & .129 & -.137. & -.001 & .053 \\
\hline $\begin{array}{l}\text { 10. How do you think that the training of teachers' skills organized } \\
\text { by the Blue Ink Cloud Class will enhance your cultural qualities? }\end{array}$ & .164 & .101. & -.464 & .304 & .445 & .131. & .042 & .076 & -.041 \\
\hline Question. 5.(A. speaks) & .000 & -.021 & .091. & .858 & .114. & .030 & .088. & .060 & .097. \\
\hline Question. 6. (A. speaks) & .155 & .110 & -.037 & .722 & -.281. & -.191. & -.104 & -.042 & -.066 \\
\hline Question-7.(A. Common office software) & -.007 & .308 & .103. & .059 & .629 & -.087 & .087. & .232. & .126. \\
\hline Question 7 (E.Nvivo) & .000 & -.033 & .060. & 195 & -.597. & .149. & .191. & .099 & .016 \\
\hline $\begin{array}{l}\text { 14. During the lecture training process, you generally tend to choose } \\
\text { how to explain the difficult and difficult points. }\end{array}$ & -.032 & .040 & -.068 & -.142 & -.170 & .755 & -.040 & .089 & -.139 \\
\hline Question-8 (D. From-life) & -.011 & .076 & .211 & .122. & -.054 & .664 & -.003 & -.008 & .431. \\
\hline Question 8.(C. Examples introduced) & .384 & -.137 & .201 & -.072 & .331. & .482 & .042 & -.236 & .092. \\
\hline Question.7.(C.Matlab) & .034 & -.086 & .003 & .031. & .045 & -.027 & .861 & -.047 & -.094 \\
\hline Question.7.(D.SPSS) & -.092 & .146. & -.109 & -.037. & -.456 & -.001. & .637. & .028 & .060. \\
\hline Question 8. (A. Mathematical Stories, Creating Situations) & 263. & -.043. & -.172 & .043. & .101. & .059 & -.057 & .714 & .022. \\
\hline Question 8 (B. Review old knowledge, introduce new knowledge) & .355. & .114. & -.177. & 141. & 394 & .126 & -.169 & -.506 & -.019 \\
\hline Question 6 (C. Lecture) & .152. & .275. & -.189 & -.004 & .218 & .060 & -.030 & 203. & .715 \\
\hline 4. Have you participated in a speech contest? & .087. & -.139 & .417. & .063. & -.157. & -.001 & -.085 & -.207. & .651 \\
\hline
\end{tabular}


It can be seen that the first common factor has a greater load on the topics and ruler graphs, mainly reflecting the students' classroom explanations skills, it is named as the classroom explanation (F1); the second factor has a large load on board writing, lectures, geometry drawing boards, and lectures. It mainly reflects students' classroom presentation skills, so it is named classroom presentation (F2); The third factor has a larger load in the field of vision, so it is named as the student's field of vision (F3); the fourth factor has a larger load in terms of opening, reflecting the students' ability to speak and opening, so it is named as a language expression ( F4); The fifth common factor has a relatively large load in terms of cultural character, mastery of mathematics software, and ability to teach in class. It reflects the cultural character of students so it is named as cultural character (F5).The sixth common factor was introduced before class. There are relatively large loads that reflect the ability of students to introduce before class. Therefore, they are named introduce before class (F6). The seventh factor has a large load on the use of math software, reflecting the students' ability to use math software, so it is named as mathematical software capabilities (F7). The eighth common factor has a greater load in cultural applications, reflecting the students' ability to apply cultural knowledge to the mathematics classroom, so it is named as the cultural application ability (F8).The ninth factor has a greater load in the lectures and lectures, reflecting the student's language ability, it is named language application(F9).

Calculate the weight of each common factor in professional skills according to the rotation component matrix as shown in Table 4.
TABLE IV. THE WEIGHT OF EACH COMPONENT IN PROFESSIONAL SKILLS

\begin{tabular}{|c|c|c|}
\hline Name & Score & Sorting \\
\hline Classroom explanation (F1) & 3.13 & 1 \\
\hline Classroom demonstration (F2) & 2.155 & 2 \\
\hline Student vision (F3) & 0.677 & 9 \\
\hline Say (F4) & 1.775 & 4 \\
\hline Cultural character (F5) & 1.074 & 7 \\
\hline Introduced before class (F6) & 1.901 & 3 \\
\hline $\begin{array}{c}\text { Mathematical software } \\
\text { capabilities (F7) }\end{array}$ & 1.498 & 5 \\
\hline $\begin{array}{l}\text { Cultural application capabilities } \\
\text { (FS) }\end{array}$ & 0.714 & 8 \\
\hline Language skills (F9) & 1.366 & 6 \\
\hline
\end{tabular}

From the table, it can be seen that the classroom explanation (F1), the classroom presentation (F2), and the introduction before class (F6) account for a large amount of weight, which has a significant effect on the promotion of professional skills.

After using the same method to obtain the rotation component matrix after professional dimension reduction, as shown in Table 5, it can be seen that the first common factor has a greater load on the attitude, which mainly reflects the enthusiasm of students' attitudes and ambitions, named the thought attitude (T1). The second common factor of the attitude has a greater load on the attitude of practice, which mainly reflects the enthusiasm of the students' practice, and is therefore named the practice attitude (T2).

TABLE V. ROTATED COMPONENT MATRIX A

\begin{tabular}{|c|c|c|}
\hline 11. Does your desire for further advanced training on the basis of existing training? & 2. .708 & .290 \\
\hline 12. Your training requirements for your teacher skills are...t & .755 & .110 \\
\hline 13. How do you think the quality of your thinking is enhanced by the teacher skill training organized by the Blue Ink Cloud Class? & .596 & .2474 \\
\hline Question 15 (A. Watch excellent video for comparison) & .430 & .1284 \\
\hline Question 15 (B. Try More on the Stage)t & 4.114 & .704 \\
\hline Question 15 (C. Actively communicate with the teacher and listen to suggestions) & $-.042+$ & .669 \\
\hline Question 15 (D. Interaction with classmates, correct each other) & $.108+$ & 609 \\
\hline 17. Do you think that there is a need for improvement in the professional skills training of normal students? & .495 & -.093 \\
\hline 18. Do you think that the current cultivation of core qualities will help future teaching work? & & -2134 \\
\hline
\end{tabular}

Next, according to the rotation component matrix, the weights of each common factor in professional literacy are calculated as shown in Table 6.

TABLE VI. THE WEIGHT OF EACH COMPONENT IN PROFESSIONAL LITERACY

\begin{tabular}{c|c|c} 
Name & Score & Sorting \\
\hline $\begin{array}{c}\text { Thought-attitude } \\
(\mathrm{T} 1)\end{array}$ & 3.676 & 1 \\
\hline $\begin{array}{c}\text { Practical-attitude } \\
(\mathrm{T} 2)\end{array}$ & 1.982 & 2
\end{tabular}

It can be seen from the table that the attitude occupies the largest weight and has a significant effect on professional literacy. It can be seen that we must pay attention to and understand the structural design of attitude teaching in teaching and skill training.

\section{The CULTIVATION PATH OF NORMAL SCIENCE STUDENTS UNDER CORE LITERACY}

Normally, people cannot compress data into two dimensions without distortion. Scholars employ "Stress" to describe the amount of distortion. We set the network size to n, 
if $9<\mathrm{n}<20$, Stress $<0.12$, which is better, if $20<\mathrm{n}<100$, Stress $<0.2$, which is also better. Using MDS to analyze' Closely related matrix' is to obtain a close relationship between teacher training skills in two-dimensional space. For qualitative survey data, Ucinet analysis and training network are used in this study to explore the cultivation path of normal science students under core literacy.

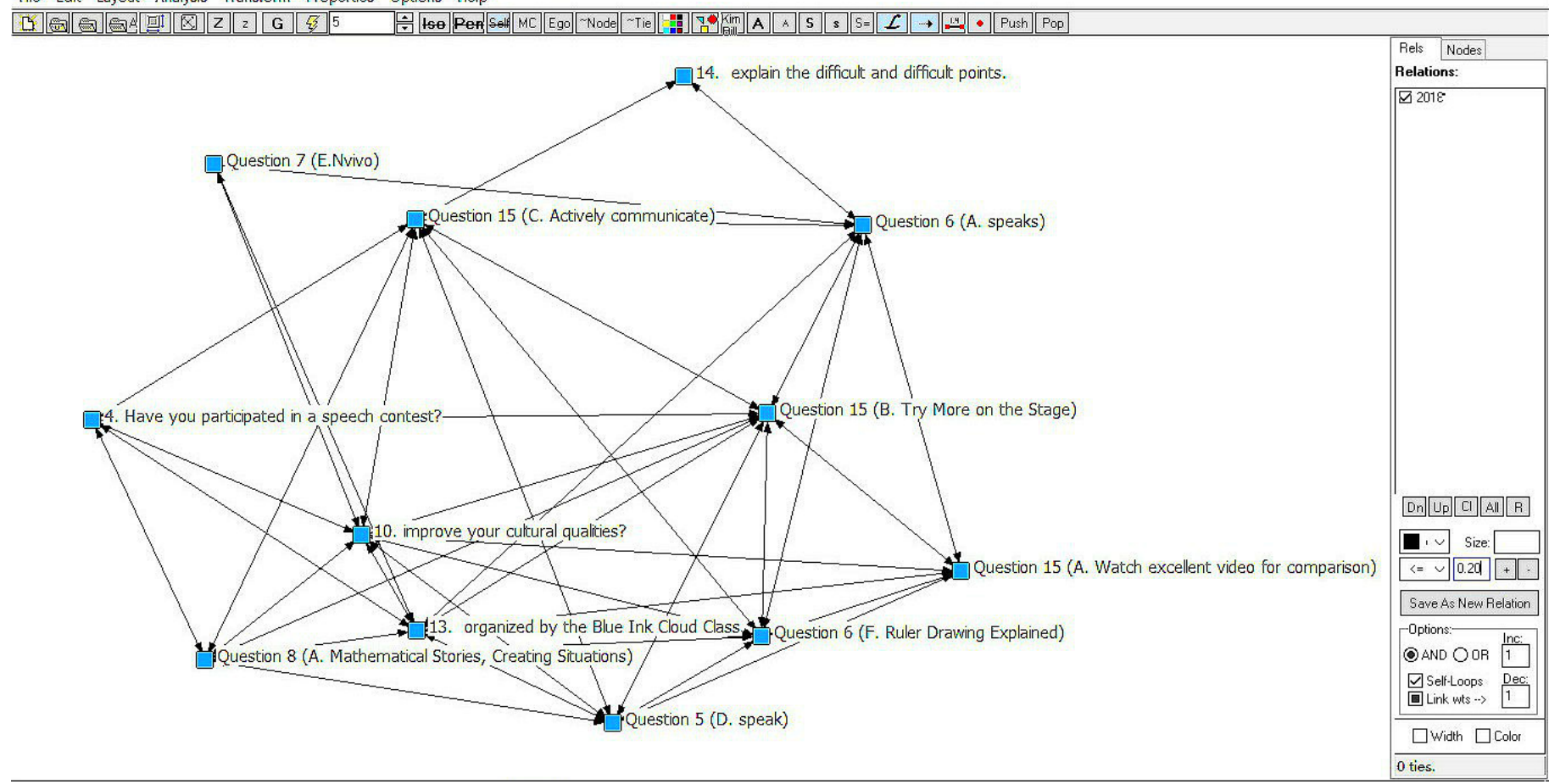

Fig. 1. Methods for teacher technical training under stress $<=0.2$

According to the intensity of the relationship, we further stratified the evaluation indicators. For example, the correlation analysis of the node's in-degree can be used to obtain an effective training path for normal science students based on certain core literacy requirements. As it is shown in Fig. 1.

Dewey said: "If we teach as we used to today, we will plunder the children's tomorrow [6]." The development of mathematics education technology has provided us with many excellent teaching software and tools. For example, Geometry Sketcher, Super Artboard, Cabri3D, Fathom Dynamic Data Software, Tinker Plots Dynamic Data Software, and Graphing Calculator. Selecting and using these technologies flexibly can promote students' mathematics learning effectively. Decision makers, researchers and teachers themselves should all agree on this.

Implementing the principle of scientific accuracy, the study conducts a comparative analysis based on survey data of normal science students in a comprehensive university. Based on this, the cultivation of normal science students can be reformed as follows:

\section{A. Do a good job in cloud teaching and innovate cultivation methods}

As normal science students, the strengthening of teacher skills training is a powerful guarantee for future teachers. It is one of the practical skills that must be mastered by Teacher
Professional students in university. Therefore, for normal science students, the necessity of teacher training is apparent. In previous years, the training of normal science students was mainly conducted in the traditional classroom teaching mode. It took a few minutes to take attendance before class each time. Teachers used projection to show excellent demonstrations of teaching videos or cases. However, the following students were easily distracted or addicted to their mobile phones, which did not achieve very good results. Based on this series of problems, the study sought to find a reformed plan under the cloud operation and big data. At the same time, during the exchanges between schools, it was learned that skills training could be carried out in conjunction with cloud teaching. Therefore, this study mainly uses Moso Teach to reform.

The experimental results show that cloud teaching is a brand-new platform, which innovates the cultivation method for normal science students. Through the cloud teaching, teachers provide excellent resources, students learn them online, practice them offline, and the effect of the experiment is remarkable. The data shows that almost $80 \%$ of the students affirmed the training effect of the cloud teaching platform, whether it is the promotion of professional skills or the training of professional qualities. 


\section{B. Connect learning resources and strengthen learning capabilities}

From the perspective of ultimate concern, education is ultimately an "adult", and human beings are human subjectivity. It lies in the existence of a kind of existential theory, lies in the existence of a kind of heart [7]. The cultivation of core literacy raises new requirements for teachers, and it is also a new requirement for normal science students. The teacher's knowledge system must be complete, so normal science students' learning ability should be strong.

The data shows that classroom presentations and classroom teaching occupy a greater weight. Classroom presentations are the ability to use math software. Classroom teaching is the application ability of the knowledge system structure. And these are all the learning abilities of normal science students. The cultivation of normal science students based on core literacy cannot be limited to basic teaching skills alone. As well as learning ability needs to be further strengthened. Normal science students are future teachers. They will face a large number of students. As the saying goes, "It is better to teach them to fish than to give them fish". Teachers give students not only knowledge, but also the ability to acquire knowledge. Therefore, the normal science students who are the predecessors of teachers must have high learning ability.

\section{Broaden students' horizons and consolidate cultural literacy}

Information explosion is fast and knowledge changes quickly. Teachers' intrinsic storage can't just be "Dead water". The result reveals that the proportion of Pre-class introduction in professional skills is relatively large. Then, which kind of pre-class introduction is successful? For one thing, it can be the repetition and consolidation, which are most basic. For another thing, it may be the introduction of life, which is appropriately natural. Of course, students are easy to understand. What's more, it is likely the introduction of mathematics culture, which can let us rub the edge of the teaching master. At present, the cultivation of normal science students requires a higher level of professional knowledge. Their professional culture is generally lower. Factually, it is far from enough.

Mathematics, it's not just mathematics; every teacher should know it clearly. Special attention should be paid to the cultivation of normal science students .Current children have a lot of access to information. Most of the current disciplines are not closed. It can be found that science exists in mathematics, physics, chemistry, or literature. All the disciplines are in the knowledge chain. They connect with each other and complement each other. Therefore, it is of great necessity to broaden the horizon of normal science students and reinforce their cultural literacy .Only in this way can they become encyclopedic experts.[8]

\section{Improve training requirements and carry out attitude construction}

Attitude is the embodiment of professional quality, and it is the improvement of the overall quality of normal science students. The survey implies that $80 \%$ of the normal science students have higher requirements for their skills and they will actively seek ways to improve themselves. Of course, there are about $10 \%$ of students, whose demand is not clear enough and their awareness is relatively low. This can be the breakthrough, which can be named 'ZDP'. They are either not trained or detached from the group. Their attitude is not clear and their requirements are not high enough. They are either not carrying out training or detaching from the group. They only have unclear attitudes and low demanding.

Nevertheless, as a teacher, attitude and literacy are extremely significant. Teachers' attitudes and professional qualities are bound to imperceptibly affect their students. Therefore, to improve training requirements in an all-round way and to establish a teacher-training degree is of utmost importance.

\section{REFERENCES}

[1] Xiuhong Li. Investigation and Research on the Present Situation of Professional Skill Cultivation of Normal College Students.[J]. Journal of Hubei Radio \& TV University.pp.117-118, 2011.( In Chinese)

[2] Yimin Liu. A Preliminary Study on Cultivation of Normal University Students' Core Literacy.[J]. Teacher Education Forum.pp.27-31, 2018.( In Chinese)

[3] Jiahua Zhu, Bin Li, Chunyang Li, Hong Cui. A Study on the Application of Virtual Simulation Experimental Platform to Faculty Students' Cultivation of Core Literacy.[J]. Laboratory research and exploration.pp.205-209, 2017.( In Chinese)

[4] Yunli Zhang, Ziqiang Zhu, Lu Chang. Study on the Status Quo and Effective Training Methods of Normal College Students' Professional Skills.[J]. Journal of Zhou Kou Normal University.pp.78-80, 2017.( In Chinese)

[5] Zhongmei Shu. Student Input Model and Learning Analysis Based on Data Mining[J]. Distance Education Magazine, Theoretical Frontier.pp.39-47, 2015.( In Chinese)

[6] Dewey,J. Democracy and education: An introduction to the philosophy of education.[M].New York: The Free Press, 1944:167.

[7] Guiqin Zhu. Reform of Practice Teaching of Teacher-training Students in the Perspective of Core Accomplishment: Direction, Dilemma and Path.[J]. Educational Development Research.pp.46-51, 2017.( In Chinese)

[8] Wugang Dan. On the Formation of Normal University Students' Core Accomplishment: From the Perspective of the Exploration of the Whole Teaching Reform of Pedagogy[J]. Journal of Henan Institute of Education.pp.71-80, 2011.( In Chinese)

[9] Dianchen Lu, Guoxing Dai, Yuting Zhang. A Preliminary Study on the Consistency of the Structural Design of Activity Design and Attitude Teaching in Blue Ink Cloud Class [J]. Cloud Teaching Theory and Practice Research Beijing Institute of Technology.pp.38-47, 201708.( In Chinese) 